\title{
AWARENESS OF 3RD SEMESTER MBBS STUDENTS REGARDING THE MEDICO-LEGAL ISSUES IN OUR SOCIETY AND THE NEED FOR TRAINING IN FORENSIC MEDICINE- A DESCRIPTIVE CROSS-SECTIONAL STUDY
}

\author{
Sadasivan Sivasuthan ${ }^{1}$, Boban Babu², Alex Varghese ${ }^{3}$, Alice David ${ }^{4}$
}

1 Professor and HOD, Department of Forensic Medicine and Toxicology, Believer's Church Medical College, Thiruvalla, Kerala, India. ${ }^{2}$ Assistant Professor, Department of Forensic Medicine and Toxicology, Believer's Church Medical College, Thiruvalla, Kerala, India. ${ }^{3}$ Assistant Professor, Department of Forensic Medicine and Toxicology, Believer's Church Medical College, Thiruvalla, Kerala, India. ${ }^{4}$ Epidemiologist and HOD, Medical Research, Believer's Church Medical College, Thiruvalla, Kerala, India.

\begin{abstract}
BACKGROUND
ABSTRACT

The instructional programmes in medical education field are aimed at developing a competent medical officer. However, the current student community gives importance only to cognitive domain, which is essential to get through postgraduate entrance tests. A medical graduate should have sufficient knowledge about medico-legal cases and his role as a responsible learned citizen in assisting the administration of law and justice in the country.
\end{abstract}

Aim: This project is an effort to get an overall picture of fresh learners before implementing a teaching programme.

\section{MATERIALS AND METHODS}

A cross-sectional, questionnaire-based study, was conducted from November 2017 to $30^{\text {th }}$ January 2018 among $3^{\text {rd }}$ semester MBBS students. Study consisted of 2 sets of questionnaires: An open ended and a closed ended. The data collected was analysed statistically.

\section{RESULTS}

A total of 71 students participated in open-ended questionnaire and 63 students participated in closed-ended questionnaire. Study showed that although more than half (54\%) were aware of medico-legal issues, many of them were not clear about everyday essential issues that affect medical profession. The students were aware of obvious legal issues such as assault (83\%) and suicide (76\%), but were not aware (scored 2 or below) of less obvious issues such as food poisoning (50\%), drunkenness (75\%), sexual offense $(71 \%)$ and accidental injury at home $(91.5 \%)$ or at school $(86 \%)$.

\section{CONCLUSION}

It was found that many students lack awareness about many day-to-day medico-legal issues. So, it would be wise to develop adequate knowledge and skill on the above at undergraduate level medical students by structured and integrated teaching programs in this regard to preserve and promote the dignity and honour of this noble profession.

\section{KEY WORDS}

Medico-Legal Issues, Awareness, Students.

HOW TO CITE THIS ARTICLE: Sivasuthan S, Babu B, Varghese A, et al. Awareness of 3rd semester MBBS students regarding the medico-legal issues in our society and the need for training in forensic medicine- a descriptive cross-sectional study. J. Evolution Med. Dent. Sci. 2018;7(36):4018-4021, DOI: 10.14260/jemds/2018/897

\section{BACKGROUND}

The instructional programmes in medical education field are aimed at developing a competent medical officer. However, the current student community gives importance only to cognitive domain, which is essential to get through postgraduate entrance tests. Every doctor should realise that irrespective of the postgraduate speciality they choose, throughout their career they have to deal with medico-legal cases. The reality in India is that, the bulk of the medico-legal works is carried out by MBBS graduates.

Practice of Community Medicine and Forensic Medicine is the major linking factor between the medical practitioners and the society at large.

'Financial or Other Competing Interest': None.

Submission 23-07-2018, Peer Review 18-08-2018,

Acceptance 25-08-2018, Published 03-09-2018.

Corresponding Author:

Dr. Sadasivan Sivasuthan,

Professor and HOD,

Department of Forensic Medicine and Toxicology,

Believer's Church Medical College,

Thiruvalla-689103, Kerala, India.

E-mail: sivasuthandr@yahoo.com

DOI: $10.14260 /$ jemds $/ 2018 / 897$
Medical schools have an obligation to produce physicians who are capable to address broad social issues relating to wellbeing. ${ }^{1}$ A medical graduate should have sufficient knowledge about medico-legal cases and his role as a responsible learned citizen in assisting the administration of law and justice in the country. But the importance of teaching and training in Forensic Medicine for the undergraduates has been undervalued in the last decade. The syllabus for undergraduate students of this important subject has been reduced over the years, hence is losing its significance. ${ }^{2}$

The general public is well aware of their rights and are literate through print and electronic media on what is happening in this field and how they should react. Now that medical care has come under the purview of consumer protection act, the responsibilities of doctors have increased, and it is mandatory to have thorough knowledge about medical jurisprudence. Hence, every medical practitioner must be adept in handling medico-legal cases, irrespective of whether they work in private clinics or government hospitals.3,4,5 Complaints against doctors seem to be on an increase in developing countries. ${ }^{6}$ Issues related to medicolegal problems and attacks on the hospitals and care providers has become a regular news item in Kerala, other parts of the 
country and worldover.7,8,9 Cases acquitted for dearth of medico-legal awareness and skill is on the rise and attracting attention of the media, judiciary and investigating agencies. Because of the above reasons, our curriculum should increase the importance of Forensic Medicine by covering all its aspects theoretically along with practical exposure under supervision and also by conducting regular medico-legal workshops. This approach shall be a competency based one.

Assessment of medico-legal awareness has already been made among medical professionals, ${ }^{9}$ postgraduate clinical trainees, ${ }^{10}$ interns and residents, ${ }^{11,12}$ practicing obstetricians and gynaecologists ${ }^{13}$ and general practitioners. ${ }^{14}$ This project is an effort to get an overall picture of fresh learners before implementing a teaching programme.

\section{MATERIALS AND METHODS}

\section{Study Design}

A cross-sectional study.

\section{Study Setting}

Study was conducted at Believers' Church Medical College Hospital, Thiruvalla, Kerala state, during the period of November 2017 to $30^{\text {th }}$ January 2018.

\section{Study Population}

The study subjects were medical students who have recently entered $3^{\text {rd }}$ semester.

\section{Sampling Method}

The study sample was selected according to purposive sampling technique.

\section{Inclusion Criteria}

Students who are in $3^{\text {rd }}$ semester. Students who were willing to take part in the study.

\section{Exclusion Criteria}

Students who were absent on the day of assessment were excluded. Students who were not willing to take part in the study.

\section{Study Tool}

This research used two questionnaires, one open-ended and a closed-ended peer reviewed questionnaire, where only the content validity was assessed by the other faculties of Forensic Medicine and other medical specialists. The closedended questionnaire had 2 broad categories: -

1. Medical practice related scenarios.

2. Scenarios related to society. Clinical scenarios were related to negligence or lack of skill on the part of a doctor; situations related to death in wards and brought dead cases. Obvious social situations such as assault or suicide and less obvious situations such as accident, food poisoning, sexual offense to a minor and drunkenness.

After getting clearance from Institutional Ethics Committee (IEC), questionnaires were distributed among students who consented and were present on the first day of Forensic Medicine class. Time given to complete the task was 20 minutes. They were asked to enumerate ten medico-legal cases, which attracted their attention in the newspapers/ electronic media from 1 ${ }^{\text {st }}$ August 2017 to 31 ${ }^{\text {st }}$ October 2017, a period of three months when they were free after their university examinations.

On the following lecture day, the peer validated closedended questionnaire was given to all students who consented and who attended the classes on that day. This questionnaire consisted of 15 clinical situations. They were asked to read and mark their answer choice against the appropriate column. The time given to complete the task was 20 minutes. The answer options ranged from strongly agree to strongly disagree. The students' identity was not considered. The two sets of questionnaires were serially numbered, but not linked to each other.

The Recovered Questionnaires were analysed as below1. Analysis of the open questionnaire- Questionnaire 1 Enumerate 10 medico-legal cases, which attracted your attention in the Newspapers/ Visual media during the last three months (1 ${ }^{\text {st }}$ August - 31 ${ }^{\text {st }}$ October 2017).

The answers were read repeatedly to identify meaning units about the participants' answers and made condensed meaning units, categorised and coded. The answers were classified into-

1. Best answer: Accurate and within specified timeframe.

2. Related answer: Accurate, but not within specified timeframe.

3. Non-related/ irrelevant/ wrong answer.

Scores were allotted as follows-

2 for best answer; 1 for related answer and 0 for wrong answer.

\section{Analysis of the Closed-Ended Questionnaire- Questionnaire 2}

Responses were graded on a gradient of $4,3,2,1$ and 0 , depending on how accurate the answer was. Those who scored 4 points were considered aware, those with 3 points as positively aware, those with 2 points as who do not know and those with either a score of 1 point or 0 point as negatively aware.

Proportions of describing the scenarios selected by the students and the proportion of awareness among the students were calculated. Graphical depiction was also done.

\section{RESULTS}

The open questionnaire was attempted by 71 students. The recovery rate was $100 \%$. Based on the open questionnaire, $54 \%$ (33\% accurate and within the timeframe $+21 \%$ accurate but not within the timeframe) of students were found aware of medico-legal cases (Table 1 and Figure 1).

The closed-ended questionnaire was attempted by 63 students. Evaluation showed $54.6 \%$ were aware of the medicolegal cases, $16.9 \%$ were positively aware, $17.4 \%$ were negatively aware and $11.0 \%$ did not know if the scenario described was a medico-legal case or not (Figure 2).

On examining each scenario, it was found that although more than half (54\%) were aware of medico-legal issues, many of them were not clear (scored 3 or below) of the 'must know items' which are everyday essential issues that affect medical professionals such as death after a definitive diagnosis was made (54\%) or not made (62\%). Similarly, in the case of lack of skill $(62 \%)$ or when patient is brought dead of unknown 
causes (48\%). However, most were aware of gross negligence $(68 \%)$ or consented therapeutic procedures (92\%).

The students were aware of obvious legal issues, such as assault (83\%) and suicide (76\%). However, they were not aware (scored 2 or below) of less obvious issues such as food poisoning (50\%), drunkenness (75\%), sexual offense (71\%), and accidental injury at home $(91.5 \%)$ or at school (86\%).

\begin{tabular}{|c|c|c|}
\hline Type of Answers & No. & Percentage \\
\hline Best & 91 & $33 \%$ \\
\hline Related & 57 & $21 \%$ \\
\hline Not Related & 125 & $46 \%$ \\
\hline Total & $\mathbf{2 7 3}$ & $\mathbf{1 0 0} \%$ \\
\hline \multicolumn{2}{|c|}{ Table 1. Distribution of the Scenarios described by the } \\
Students \\
\hline
\end{tabular}

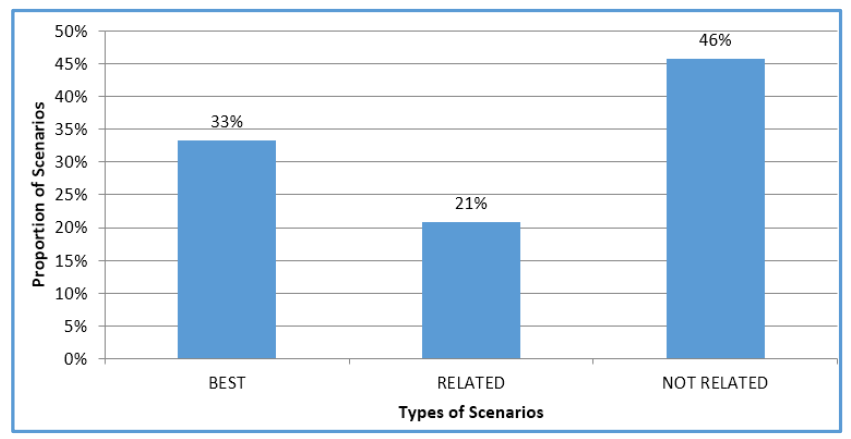

Figure 1. Distribution of the Scenarios described by the Students

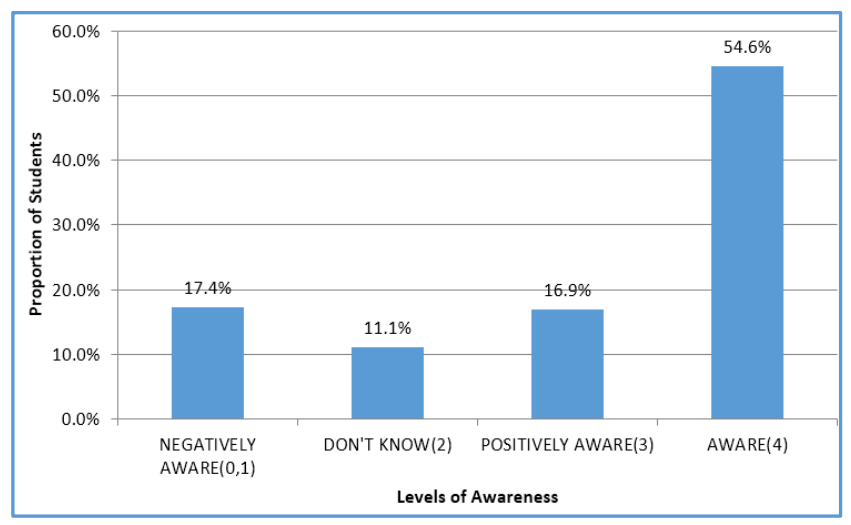

Figure 2. Distribution of the Level of Awareness among the Students

\section{DISCUSSION}

Various awareness studies on medico-legal aspects of medical practice has been conducted on general medical practitioners, medical specialist practitioners, residents, interns and other health professionals in several parts of the world. Medical professionals are becoming more and more aware of the significance of ethical, moral and medico-legal aspects of their profession and are more conscious and cautious on unethical practices and medical negligence cases.

Fresh medical students who have not been introduced to Forensic Medicine classes were only aware of the most obvious medico-legal issues. Their awareness of less obvious scenarios and especially scenarios related to clinical practice was poor.

\section{CONCLUSION}

Therefore, it would be wise to develop adequate knowledge and skill on the above at undergraduate level medical students by structured and integrated teaching programs in this regard to preserve and promote the dignity and honour of this noble profession.

Before we sow the seeds, we should know the soil. This study was an attempt to know the learners before implementing a teaching program.

The limitation of the study is that the rights of the doctors were not addressed in the questionnaire.

\section{ACKNOWLEDGEMENT}

I most sincerely acknowledge the Convener MCI Nodal Centre, GMC, Kottayam and the faculty for their support and guidance. I acknowledge the earnest help and guidance of Dr. Pramod Thomas, Assistant Professor of Statistics, BCMCH, Thiruvalla.

\section{REFERENCES}

[1] Nancy GE, Charles B, Barbara G, et al. Improving the social responsiveness of medical schools. Proceedings of the 1998 Educational Commission for Foreign Medical Graduates/World Health Organization Invitational Conference. Acad Med 1999;74(Suppl 8):S3-S94.

[2] Mardikar PA, Kasulkar AA. To assess the need of medicolegal education in interns and residents in medical institution. J of Evolution of Med and Dent Sci 2015;4(17):2885-9.

[3] Sharma BR, Harish D, Chavali KH. Teaching, training and practice of Forensic Medicine in India: an overview. J Indian Acad Forensic Med 2005;27(4):247-51.

[4] Dash SK. Medical ethics, duties and medical negligence awareness among the practitioners in a teaching medical college, hospital - a survey. J Indian Acad Forensic Med 2010;32(2):153-6.

[5] Gebrimariam T, Hagos MB. Situation analysis of medico-legal issues in Asmara, Eritrea in 2008. Journal of Eritrean Medical Association 2008;4:34-6.

[6] Mittal S, Sonia G, Moneeshindra SM. Need of forensic medicine in trauma care. Medico-Legal Update 2007;7(3):81-6.

[7] Goodman RA, Jenkins EL, Mercy JA. Workplace related homicide among health care workers in the United States, 1980 through 1990. JAMA 1994;272(21):16868.

[8] Mayeda M, Takase K. Need for enforcement of ethical education - an analysis of survey on post graduate clinical trainees. BMC Medical Ethics 2005;6:8.

[9] Kheir AEM, Dafaalla M, Bashir AA, et al. Medicolegal awareness among health professionals in Sudan Where are we now? Online Journal of Clinical Adults 2016;8(4).

[10] Rai JJ, Acharya RV, Dave D. Knowledge and awareness among interns and residents about Medical Law and negligence in Medical College Vadodara - a questionnaire study. Journal of Dental and Medical Sciences 2013;3(4):32-8. 
[11] Rao GV, Hari N. Medico-legal knowledge assessment of interns and post graduate students in a medical institution. IAIM 2016;3(10):105-10.

[12] Nanandkar SD, Chavan GS. Assessment of medico legal awareness of practicing Obstetricians and Gynecologists. Journal of Indian Academy of Forensic Medicine 2008;30(3):136-40.
[13] Chavda KL, Jadav JC, Rakesh Y, et al. A study on awareness and Consciousness towards the different medico legal terms among the doctors of different areas of Gujarat. Int J Res Med 2014;3(4):43-5.

[14] Elizabeth A. Modern moral philosophy, religion and politics. Oxford: Blackwell 2002;43:345-9. 